\title{
Recent Advances in Stem Cell-Based Therapeutics for Stroke
}

\author{
Eleonora Napoli ${ }^{1}$ C Cesar V. Borlongan ${ }^{2}$
}

Received: 1 August 2016 / Accepted: 3 August 2016/Published online: 12 August 2016

(C) Springer Science+Business Media New York 2016

\section{Regenerative Medicine Circumvents Short Therapeutic Window of Stroke}

Regenerative medicine has advanced the efficacy of exogenous and endogenous stem cells in restoring central nervous system disorders (CNS) in the aged and diseased brain [1-3]. Stem cell therapy has been examined in numerous neurological disorders, with highly encouraging results suggesting its indication as a stroke treatment [4-6]. In this regard, despite the availability of the thrombolytic agent tissue plasminogen activator (tPA) for stroke, its narrow therapeutic window and associated adverse events have not resolved the disease stigma as a major cause of mortality and morbidity around the world. Because stem cell therapy targets the subacute and chronic phases of stroke, thereby significantly extending the effective time of intervention, many patients are likely to benefit from this treatment. Several types of transplantable cells have been tested in the laboratory, with a few reaching clinical trials for cell therapy in stroke, including fetal cells, NT2N cells, CTX0E3, embryonic stem cells, neural stem/progenitor cells, umbilical cord blood, amnion, adipose, and induced pluripotent stem cells [7-12]. Primarily, due to solid safety profile in other disease indications, preclinical studies and ongoing clinical trials have given special attention to bone marrow and its cellular derivatives $[13,14]$. Direct intracerebral implantation and peripheral transplantation, such as intravenous, intra-

Cesar V. Borlongan

cborlong@health.usf.edu

1 Department of Molecular Biosciences, University of California Davis, Davis, CA, USA

2 Center of Excellence for Aging and Brain Repair, Department of Neurosurgery and Brain Repair, University of South Florida College of Medicine, 12901 Bruce B. Downs Blvd, Tampa, FL 33612, USA arterial, and intranasal, have documented the functional benefits of bone marrow-derived stem cells [13, 15-18]. Clinical trials have been initiated, and preliminary reports have demonstrated safety, although efficacy warrants additional investigations [14]. Here, we discuss the various sources and profiles of stem cells, with particular interest in the adult tissuederived mesenchymal stem cells, their use in cell transplantation, translational challenges, and putative need for adjunctive therapies. Finally, we reflect on the current societal views that stem cell therapy in general has provoked in the public domain. Our goal is to assess the science behind regenerative medicine in an effort to advance the safe, effective, and mechanism-based application of cell therapy for stroke.

\section{So Many Choices, but We Need to Identify the Best Stem Cell}

Among the several factors such as cell route, dose, and timing of administration, the specific type of stem cells is key to the outcome of cell transplantation [19-21]. From the initial study of fetal cell transplantation into stroke animals, varying levels of histological and behavioral recovery have been demonstrated in NT2N, CTX0E3, embryonic stem cells, hematopoietic stem cells, neural stem cells, adult tissue-derived stem cells, and induced pluripotent stem cells [7-11, 22]. The quest for the optimal cell type for transplantation therapy has largely been dictated by ethical and logistical issues [23, 24]. Fetal and embryonic cells have been primarily hampered by the ethics governing their isolation, while the generation of an ample supply of cells that truly recapitulate "stemness" has been the logistical challenge for the other cell types. Because of the adult tissue origin and the resemblance with many of the stem cell phenotypic features, bone marrow-derived stem cells have emerged as leading transplantable cell type for CNS disorders, 
including stroke [25]. Specialized subsets or populations, as well as engineered stem/progenitor cells, have been derived from the bone marrow, including mesenchymal stem or stromal cells (MSCs), endothelial progenitor cells (EPCs), SB623, multipotent adult progenitor cells (MAPCs), multilineagedifferentiating stress enduring (Muse), among many others [26-30]. Among these bone marrow-derived cells, MSCs have been extensively studied in stroke animal models. MSCs have been shown to exhibit adult multipotency characteristics, capable of differentiation toward various cell lineages both in vitro and in vivo [13, 16, 31-34]. Following their transplantation in stroke models, MSCs produced functional recovery, including reduction in brain damage and improvement of motor and cognitive performance [35]. Postulated mechanisms of action include cell replacement, growth factor secretion, and promotion of endogenous brain repair processes, including neurogenesis, angiogenesis, and synaptogenesis, which are triggered by the grafted MSCs themselves or their secreted factors or exosomes [36-40]. Although stem cells are considered biologics, assessment of their clinical applications seemed initially influenced by the ligand-receptor mechanism usually ascribed to drugs. Accordingly, a reductionist single regenerative pathway accompanied the quest for determining the mode of action underlying cell therapy for stroke. However, we now recognize the multipronged cell death processes that plague stroke that likely will be best sequestered by the stem cells' multiple regenerative functions [41-43]. This complexity of the disease process will also necessitate not a stand-alone cell therapy, but a combination of therapies, including potent drugs and biomaterials which in tandem may facilitate the functional outcomes of stem cell-based therapeutics (to be discussed in detail below).

\section{The Jury Has Partially Spoken: MSCs Are Safe, but Their Efficacy Remains Inconclusive}

Intravenous administration of autologous MSCs has been tested in limited clinical trials. Improvements in neurological outcomes, including Barthel index and Rankin scale, were noted following delayed (initial infusion at 4 weeks after disease onset) autologous transplantation of 100 million MSCs (SH2 and SH-4 positive) in five stroke patients, although the functional benefits appeared to wane by 12 months posttransplantation [44]. No adverse events were observed in this randomized trial [44]. A similar autologous intravenous bone marrow transplantation, but this time using 7-10 million mononuclear cells (MNCs) per kilogram delivered acutely (24 and $72 \mathrm{~h}$ after stroke), produced more robust improvements in Barthel index, modified Rankin scale, and National Institutes of Health Stroke Scale (NIHSS) over a 6-month period in many of the transplanted patients [45]. No adverse events were also reported in this open-labeled study [45]. Building upon this initial bone marrow-derived MNC stroke trial, a phase II, multicenter, parallel group, randomized trial with blinded outcome assessment that included 120 patients was conducted in India [15]. Results revealed that stroke patients $(n=58)$ who received a mean of 280.75 million MNCs at median of 18.5 days after stroke onset did not differ in the Barthel index score, modified Rankin scale shift analysis, NIHSS score, or infarct volume compared to nontransplanted stroke patients at 6-month post-transplantation [15]. This randomized study showed that intravenous transplantation MNCs is safe but not effective for subacute stroke. A smaller population of bone marrow MNCs which are CD34+ was the basis of another stroke trial that involved intra-arterial delivery of 100 million autologous, immunoselected CD34+ stem/progenitor cell in stroke patients $(n=5)$ presenting within 7 days of onset with severe anterior circulation ischemic stroke (NIHSS score of $\geq 8$ ) [46]. All transplanted stroke patients exhibited improvements in the modified Rankin scale and NIHSS score, coupled with reductions in lesion volume during a 6-month follow-up period. The procedure was well tolerated in all patients, and no significant treatment-related adverse effects occurred. This openlabeled study revealed that intra-arterial delivery of bone marrow MNC-derived CD34+ cells is safe [46].

A careful review of these clinical trials revealed that transplantation of MSCs and their cellular derivatives (including MNCs) is safe in stroke. However, with small number of patients and the open-labeled approach (except the Prasad study), the efficacy of MSCs in stroke remains to be determined. Further scrutiny of the trials also exposed discrepancies across the trials themselves that limit direct cross-study evaluations. Equally disappointing is the disconnection between the laboratory and clinical transplant regimens. Apparent from these clinical transplant protocols are the differences in donor cells, which as noted in our overarching premise is likely to dictate the functional outcomes of stem cell therapy. Bang and colleagues have used the $\mathrm{SH}-2$ and $\mathrm{SH}-4$ as released criteria of their cells [44], Savitz and collaborators used an extensive panel of antibodies (CD3, CD14, CD16, CD19, CD20, CD34, CD45, CD56, Lin 1, CD133-2) for flow cytometry to define MNCs [45], Prasad and co-workers also used flow cytometry to identify MNCs but focused only on CD34 and CD45 [15], and Banerjee and colleagues used magnetic cell isolation procedure to harvest purified CD34+ cells [46]. Clearly, based on this donor cell starting material alone, comparisons of the outcomes from the four trials will be inconclusive. Moreover, the timing of intervention significantly varied across trials: 4 weeks, days 1-3, 18.5 days, and within 7 days of stroke onset for Bang, Savitz, Prasad, and Banerjee trials, respectively. Additionally, the route of delivery differed, being intravenous route for the Bang, Savitz, and Prasad, and intra-arterial for Banerjee. Compared with 
the preclinical studies of many stem cells, MSCs included, the effective dose range of intravenous delivery is about 4 million cells in a $250 \mathrm{~g}$ rat which translates to around 840 million cells in a $75 \mathrm{~kg}$ human being [47] indicating that the dose these clinical trials utilized are well below the threshold to recognize any efficacy readout. An exception is the Savitz's trial that closely approximated the preclinical cell dose and resulted in many patients showing clinical improvement, although efficacy needs to be cautiously interpreted as this was an openlabeled study. A search of the literature revealed scarce reported studies supporting the characterization of safety, efficacy, and mechanism of action, along the Stem cell Therapeutics as an Emerging Paradigm for Stroke (STEPS) lab-to-clinic translational guidelines [19], for each defined donor type used in each clinical trial except for the Savitz's group. Adherence to the STEPS guidelines of future clinical trials, allowing the science to form the basis of the clinical trial design, is likely to enhance the successful translation of stem cell-based therapeutics for clinical applications.

\section{Cell Therapy: from Standing Alone to Synergic Regenerative Processes}

\section{Driving Stem Cells Under the Influence of Drugs}

The safety and efficacy of tPA as stroke therapeutics are confined to a relatively small population of ischemic stroke patients because of its narrow therapeutic window, within $4.5 \mathrm{~h}$ of stroke onset. Extending this limited effective window for intervention has proven a challenge for many chemicals, peptides, or trophic factors; thus, many pharmaceutical companies have avoided research and development of drugs for stroke. However, two major new breeds of drugs targeting the subacute and chronic phases of the disease appear to revive excitement in drug therapy for stroke, namely biological compounds that enhance neurogenesis/angiogenesis/synaptogenesis and those that abrogate inflammation [48-50]. Among these candidate drugs tested in stroke models, and a few reaching limited clinical trials, are statins [51-53], G-CSF $[8,54,55]$, erythropoietin [56-59], candesartan [51, 52], metformin $[60,61]$, minocycline [62], apurinic/apyrimidinic siterepairing enzyme endonuclease-1 [63], isoxazole-9 [64], arachidonic acid metabolites such as lipoxin A4 [65], and recombinant $\mathrm{T}$ cell receptor ligands [66, 67]. Of note, MSCs have been shown to induce both neurogenesis and antiinflammation $[18,68,69]$, suggesting that an additive effects may be achieved by combining MSCs and drugs that act on these two regenerative pathways. Indeed, this stem cell-drug combination therapy has been a recent topic of much interest in cell therapy for stroke [8]. Recent non-pharmacological approaches shown to augment neurogenesis and to dampen inflammation in stroke have involved remote ischemic conditioning [70-75] and localized cerebral hypothermia [76]. Rigorous preclinical studies will be needed to translate combination therapies for clinical applications in stroke.

\section{Cradling Stem Cells in a Microenvironment Conducive for Regeneration}

The ischemic brain arising from stroke is characterized by hostile neural tissue that is not conducive for exogenous and endogenous stem cells to survive and to initiate regeneration. The use of hydrogels and other biomaterials in neural tissue regeneration may aid in remodeling the ischemic brain [77]. Acellular extracellular matrix has been shown to stimulate the infiltration of host brain cells while sequestering necrotic debris from the injury. Such hydrogel treatment is capable of promoting an endogenous stem cell-mediated repair response [77] but could also induce a favorable microenvironment for improved survival of exogenous stem cells that could be vital for initiating regeneration of the stroke brain [78]. In particular, hydrogels can serve as scaffolds to support interactions between the host and transplanted tissues, occupy the tissue cavity or necrotic core, and regulate localized delivery of stem cell-secreted therapeutic molecules [77, 79]. This biomaterial modifies the poststroke microenvironment to become suitable for implantation of exogenous stem cells and also nurtures endogenous stem cells towards creating a niche for neurogenesis [80]. Similar to drugs, the use of biomaterials as an adjunct treatment to cell-based therapeutics will require translational research to find the optimal fabrication that is safe and effective in harnessing regenerative medicine in stroke.

\section{Challenges in Stem Cell Therapy: Missing Controls and Public Perception}

Rehabilitation therapy is the standard treatment for stroke survivors [81, 82]. Surprisingly, rehabilitation therapy has been neglected as a control arm for most, if not all, of the preclinical studies and ongoing clinical trials of cell therapy for stroke. In order to fully capture the therapeutic benefits of cell therapy, incorporation of rehabilitation therapy will be paramount in both transplanted stroke animals and patients.

The ascent of stem cell use in science has been accompanied by a public concern about their tissue origin and commercialization [24]. The media has exploited the ethical controversy surrounding the fetal and embryonic origin stem cells, fostering public fear and misperception of commercialization of stem cells that has contributed to medical tourism. A consortium that will convene the layman public with stem cell experts is likely to resolve many concerns about the bioethics of stem cells [23]. 


\section{Conclusion}

The aging and diseased brain can be regenerated. Stem cell therapy for stroke has garnered sufficient scientific evidence to proceed towards limited clinical trials. Solid safety profiles of MSCs in other disease indications make these cells appealing as donor cells for transplantation in stroke. Rigorous preclinical studies further support MSC transplantation in stroke patients. However, preliminary reports from completed and ongoing clinical trials of cell therapy in stroke indicate safety but not efficacy owing in large part to obvious deviations of the clinical protocols from the optimal transplant regimen established in the laboratory. In particular, the current dose in the clinic is at least eightfold lower than the dose observed to be effective in stroke animals. Allowing science to guide the clinical trial design is likely to improve the outcome of cell therapy in stroke. A vis-à-vis comparison between stem cell therapy and rehabilitation therapy, which is the current gold standard of stroke care, will provide stringent assessment of the therapeutic effects of this regenerative medicine. The public concern on the bioethics of stem cells needs to be addressed as we move forward with both laboratory and clinical investigations of cell therapy for stroke.

Acknowledgments CVB is funded by NIH R01NS071956, NIH R01 NS090962, NIH R21NS089851, NIH R21 NS094087, DOD W81XWH11-1-0634, and VA Merit Review I01 BX001407.

\section{Compliance with Ethical Standards}

Conflict of Interest CVB received research grants from NIH, NeuralStem, Karyopharm, SanBio Inc. and has patent applications related to stem cell therapy with Athersys Inc. and SanBio Inc. EN declares that she has no conflict of interest.

Ethics Approval This article does not contain any studies with human participants or animals performed by any of the authors.

\section{References}

1. Muotri AR, Gage FH. Generation of neuronal variability and complexity. Nature. 2006;441:1087-93.

2. Lindvall O, Kokaia Z. Stem cells for the treatment of neurological disorders. Nature. 2006;441:1094-6.

3. Androutsellis-Theotokis A, Leker RR, Soldner F, Hoeppner DJ, Ravin R, Poser SW, et al. Notch signalling regulates stem cell numbers in vitro and in vivo. Nature. 2006;442:823-6.

4. Chen J, Venkat P, Zacharek A, Chopp M. Neurorestorative therapy for stroke. Front Hum Neurosci. 2014;8:382.

5. Boltze J, Lukomska B, Jolkkonen J. Consortium M-I. Mesenchymal stromal cells in stroke: improvement of motor recovery or functional compensation? J Cereb Blood Flow Metab. 2014;34:1420-1.

6. Borlongan CV. Age of PISCES. Lancet. 2016; In press.

7. Stroemer P, Patel S, Hope A, Oliveira C, Pollock K, Sinden J. The neural stem cell line CTX0E03 promotes behavioral recovery and endogenous neurogenesis after experimental stroke in a dosedependent fashion. Neurorehabil Neural Repair. 2009;23:895-909.

8. De La Pena I, Sanberg PR, Acosta S, Lin SZ, Borlongan CV. G-CSF as an adjunctive therapy with umbilical cord blood cell transplantation for traumatic brain injury. Cell Transplant. 2015;24:447-57.

9. Hara K, Yasuhara T, Maki M, Matsukawa N, Masuda T, Yu SJ, et al. Neural progenitor NT2N cell lines from teratocarcinoma for transplantation therapy in stroke. Prog Neurobiol. 2008;85:318-34.

10. Kaneko Y, Hayashi T, Yu S, Tajiri N, Bae EC, Solomita MA, et al. Human amniotic epithelial cells express melatonin receptor MT1, but not melatonin receptor MT2: a new perspective to neuroprotection. J Pineal Res. 2011;50:272-80.

11. Liu SP, Fu RH, Wu DC, Hsu CY, Chang CH, Lee W, et al. Mouseinduced pluripotent stem cells generated under hypoxic conditions in the absence of viral infection and oncogenic factors and used for ischemic stroke therapy. Stem Cells Dev. 2014;23:421-33.

12. Li Z, McKercher SR, Cui J, Nie Z, Soussou W, Roberts AJ, et al. Myocyte enhancer factor $2 \mathrm{C}$ as a neurogenic and antiapoptotic transcription factor in murine embryonic stem cells. J Neurosci. 2008;28:6557-68.

13. Borlongan CV, Glover LE, Tajiri N, Kaneko Y, Freeman TB. The great migration of bone marrow-derived stem cells toward the ischemic brain: therapeutic implications for stroke and other neurological disorders. Prog Neurobiol. 2011;95:213-28.

14. Steinberg GK, Kondziolka D, Wechsler LR, Lunsford LD, Coburn ML, Billigen JB, et al. Clinical outcomes of transplanted modified bone marrow-derived mesenchymal stem cells in stroke: a phase 1/ 2a study. Stroke. 2016;47:1817-24.

15. Prasad K, Sharma A, Garg A, Mohanty S, Bhatnagar S, Johri S, et al. Intravenous autologous bone marrow mononuclear stem cell therapy for ischemic stroke: a multicentric, randomized trial. Stroke. 2014;45:3618-24.

16. Borlongan CV. Bone marrow stem cell mobilization in stroke: a 'bonehead' may be good after all! Leukemia. 2011;25:1674-86.

17. Borlongan CV, Lind JG, Dillon-Carter O, Yu G, Hadman M, Cheng $\mathrm{C}$, et al. Intracerebral xenografts of mouse bone marrow cells in adult rats facilitate restoration of cerebral blood flow and bloodbrain barrier. Brain Res. 2004;1009:26-33.

18. Acosta SA, Tajiri N, Hoover J, Kaneko Y, Borlongan CV. Intravenous bone marrow stem cell grafts preferentially migrate to spleen and abrogate chronic inflammation in stroke. Stroke. 2015:46:2616-27.

19. Savitz SI, Cramer SC, Wechsler L, Consortium S. Stem cells as an emerging paradigm in stroke 3: enhancing the development of clinical trials. Stroke. 2014;45:634-9.

20. Savitz SI, Chopp M, Deans R, Carmichael T, Phinney D, Wechsler $\mathrm{L}$, et al. Stem cell therapy as an emerging paradigm for stroke (STEPS) II. Stroke. 2011;42:825-9.

21. Stem Cell Therapies as an Emerging Paradigm in Stroke P. Stem cell therapies as an emerging paradigm in stroke (STEPS): bridging basic and clinical science for cellular and neurogenic factor therapy in treating stroke. Stroke. 2009;40:510-5.

22. Borlongan CV, Fournier C, Stahl CE, Yu G, Xu L, Matsukawa N, et al. Gene therapy, cell transplantation and stroke. Front Biosci. 2006;11:1090-101.

23. Borlongan CV, McWhirter C, Fultz-Carver C, Fitzgerald KT, Sanberg PR. The case for an ethics research consortium for emerging technologies: public perception of stem cell research and development. Technol Innov. 2010;12:21-8.

24. Lo B, Parham L. Ethical issues in stem cell research. Endocr Rev. 2009;30:204-13.

25. Tang Y, Yasuhara T, Hara K, Matsukawa N, Maki M, Yu G, et al. Transplantation of bone marrow-derived stem cells: a promising therapy for stroke. Cell Transplant. 2007;16:159-69.

26. Gnecchi M, Melo LG. Bone marrow-derived mesenchymal stem cells: isolation, expansion, characterization, viral 
transduction, and production of conditioned medium. Methods Mol Biol. 2009;482:281-94.

27. Li YF, Ren LN, Guo G, Cannella LA, Chernaya V, Samuel S, et al. Endothelial progenitor cells in ischemic stroke: an exploration from hypothesis to therapy. J Hematol Oncol. 2015;8:33.

28. Yasuhara T, Matsukawa N, Hara K, Maki M, Ali MM, Yu SJ, et al. Notch-induced rat and human bone marrow stromal cell grafts reduce ischemic cell loss and ameliorate behavioral deficits in chronic stroke animals. Stem Cells Dev. 2009;18:1501-14.

29. Yasuhara T, Hara K, Maki M, Mays RW, Deans RJ, Hess DC, et al. Intravenous grafts recapitulate the neurorestoration afforded by intracerebrally delivered multipotent adult progenitor cells in neonatal hypoxic-ischemic rats. J Cereb Blood Flow Metab. 2008;28:1804-10.

30. Uchida H, Morita T, Niizuma K, Kushida Y, Kuroda Y, Wakao S, et al. Transplantation of unique subpopulation of fibroblasts, muse cells, ameliorates experimental stroke possibly via robust neuronal differentiation. Stem Cells. 2016;34:160-73.

31. Rowart P, Erpicum P, Detry O, Weekers L, Gregoire C, Lechanteur $\mathrm{C}$, et al. Mesenchymal stromal cell therapy in ischemia/reperfusion injury. J Immunol Res. 2015;2015:602597.

32. Eckert MA, Vu Q, Xie K, Yu J, Liao W, Cramer SC, et al. Evidence for high translational potential of mesenchymal stromal cell therapy to improve recovery from ischemic stroke. J Cereb Blood Flow Metab. 2013;33:1322-34.

33. Kocsis JD, Honmou O. Bone marrow stem cells in experimental stroke. Prog Brain Res. 2012;201:79-98.

34. Joyce N, Annett G, Wirthlin L, Olson S, Bauer G, Nolta JA. Mesenchymal stem cells for the treatment of neurodegenerative disease. Regen Med. 2010;5:933-46.

35. van Velthoven CT, Gonzalez F, Vexler ZS, Ferriero DM. Stem cells for neonatal stroke — the future is here. Front Cell Neurosci. 2014;8:207.

36. Doeppner TR, Hermann DM. Mesenchymal stem cells in the treatment of ischemic stroke: progress and possibilities. Stem Cells Cloning. 2010;3:157-63.

37. Anderson JD, Johansson HJ, Graham CS, Vesterlund M, Pham MT, Bramlett CS, et al. Comprehensive proteomic analysis of mesenchymal stem cell exosomes reveals modulation of angiogenesis via nuclear factor-kappaB signaling. Stem Cells. 2016;34:601-13.

38. Duffy GP, Ahsan T, O’Brien T, Barry F, Nerem RM. Bone marrowderived mesenchymal stem cells promote angiogenic processes in a time- and dose-dependent manner in vitro. Tissue Eng Part A. 2009;15:2459-70.

39. Xiong Y, Mahmood A, Chopp M. Angiogenesis, neurogenesis and brain recovery of function following injury. Curr Opin Investig Drugs. 2010;11:298-308.

40. Ishikawa H, Tajiri N, Shinozuka K, Vasconcellos J, Kaneko Y, Lee $\mathrm{HJ}$, et al. Vasculogenesis in experimental stroke after human cerebral endothelial cell transplantation. Stroke. 2013;44:3473-81.

41. Schweizer S, Meisel A, Marschenz S. Epigenetic mechanisms in cerebral ischemia. J Cereb Blood Flow Metab. 2013;33:1335-46.

42. Puyal J, Ginet V, Clarke PG. Multiple interacting cell death mechanisms in the mediation of excitotoxicity and ischemic brain damage: a challenge for neuroprotection. Prog Neurobiol. 2013;105:24-48.

43. Sozmen EG, Hinman JD, Carmichael ST. Models that matter: white matter stroke models. Neurotherapeutics. 2012;9:349-58.

44. Bang OY, Lee JS, Lee PH, Lee G. Autologous mesenchymal stem cell transplantation in stroke patients. Ann Neurol. 2005;57:874-82.

45. Savitz SI, Misra V, Kasam M, Juneja H, Cox Jr CS, Alderman S, et al. Intravenous autologous bone marrow mononuclear cells for ischemic stroke. Ann Neurol. 2011;70:59-69.

46. Banerjee S, Bentley P, Hamady M, Marley S, Davis J, Shlebak A, et al. Intra-arterial immunoselected CD34+ stem cells for acute ischemic stroke. Stem Cells Transl Med. 2014;3:1322-30.

47. Diamandis T, Borlongan CV. One, two, three steps toward cell therapy for stroke. Stroke. 2015;46:588-91.
48. Chen S, Yang Q, Chen G, Zhang JH. An update on inflammation in the acute phase of intracerebral hemorrhage. Transl Stroke Res. 2015;6:4-8.

49. Xiong XY, Yang QW. Rethinking the roles of inflammation in the intracerebral hemorrhage. Transl Stroke Res. 2015;6:339-41.

50. Hosaka K, Hoh BL. Inflammation and cerebral aneurysms. Transl Stroke Res. 2014;5:190-8.

51. Chen J, Zhang ZG, Li Y, Wang Y, Wang L, Jiang H, et al. Statins induce angiogenesis, neurogenesis, and synaptogenesis after stroke. Ann Neurol. 2003;53:743-51.

52. White HD, Simes RJ, Anderson NE, Hankey GJ, Watson JD, Hunt $\mathrm{D}$, et al. Pravastatin therapy and the risk of stroke. N Engl J Med. 2000;343:317-26.

53. Reuter B, Rodemer C, Grudzenski S, Meairs S, Bugert P, Hennerici MG, et al. Effect of simvastatin on MMPs and TIMPs in human brain endothelial cells and experimental stroke. Transl Stroke Res. 2015;6:156-9.

54. Pena I, Borlongan CV. Translating G-CSF as an adjunct therapy to stem cell transplantation for stroke. Transl Stroke Res. 2015;6:421-9.

55. Yamauchi T, Saito H, Ito M, Shichinohe H, Houkin K, Kuroda S. Platelet lysate and granulocyte-colony stimulating factor serve safe and accelerated expansion of human bone marrow stromal cells for stroke therapy. Transl Stroke Res. 2014;5:701-10.

56. Ding G, Jiang Q, Li L, Zhang L, Wang Y, Zhang ZG, et al. Cerebral tissue repair and atrophy after embolic stroke in rat: a magnetic resonance imaging study of erythropoietin therapy. J Neurosci Res. 2010;88:3206-14.

57. Gonzalez FF, Larpthaveesarp A, McQuillen P, Derugin N, Wendland M, Spadafora R, et al. Erythropoietin increases neurogenesis and oligodendrogliosis of subventricular zone precursor cells after neonatal stroke. Stroke. 2013;44:753-8.

58. Wang L, Zhang Z, Wang Y, Zhang R, Chopp M. Treatment of stroke with erythropoietin enhances neurogenesis and angiogenesis and improves neurological function in rats. Stroke. 2004;35:1732-7.

59. Souvenir R, Flores JJ, Ostrowski RP, Manaenko A, Duris K, Tang J. Erythropoietin inhibits HIF-1alpha expression via upregulation of PHD-2 transcription and translation in an in vitro model of hypoxiaischemia. Transl Stroke Res. 2014;5:118-27.

60. Ishrat T, Pillai B, Ergul A, Hafez S, Fagan SC. Candesartan reduces the hemorrhage associated with delayed tissue plasminogen activator treatment in rat embolic stroke. Neurochem Res. 2013;38:2668-77.

61. Abdelsaid M, Prakash R, Li W, Coucha M, Hafez S, Johnson MH, et al. Metformin treatment in the period after stroke prevents nitrative stress and restores angiogenic signaling in the brain in diabetes. Diabetes. 2015;64:1804-17.

62. Fagan SC, Cronic LE, Hess DC. Minocycline development for acute ischemic stroke. Transl Stroke Res. 2011;2:202-8.

63. Leak RK, Li P, Zhang F, Sulaiman HH, Weng Z, Wang G, et al. Apurinic/apyrimidinic endonuclease 1 upregulation reduces oxidative DNA damage and protects hippocampal neurons from ischemic injury. Antioxid Redox Signal. 2015;22:135-48.

64. Koh SH, Liang AC, Takahashi Y, Maki T, Shindo A, Osumi N, et al. Differential effects of isoxazole-9 on neural stem/progenitor cells, oligodendrocyte precursor cells, and endothelial progenitor cells. PLoS One. 2015;10:e138724.

65. Guo Z, Hu Q, Xu L, Guo ZN, Ou Y, He Y, et al. Lipoxin A4 reduces inflammation through formyl peptide receptor 2/p38 MAPK signaling pathway in subarachnoid hemorrhage rats. Stroke. 2016;47:490-7.

66. Zhu W, Casper A, Libal NL, Murphy SJ, Bodhankar S, Offner H, et al. Preclinical evaluation of recombinant $\mathrm{T}$ cell receptor ligand RTL1000 as a therapeutic agent in ischemic stroke. Transl Stroke Res. 2015;6:60-8.

67. Zhu W, Libal NL, Casper A, Bodhankar S, Offner H, Alkayed NJ. Recombinant $\mathrm{T}$ cell receptor ligand treatment improves neurological outcome in the presence of tissue plasminogen activator in experimental ischemic stroke. Transl Stroke Res. 2014;5:612-7. 
68. Jeong CH, Kim SM, Lim JY, Ryu CH, Jun JA, Jeun SS. Mesenchymal stem cells expressing brain-derived neurotrophic factor enhance endogenous neurogenesis in an ischemic stroke model. Biomed Res Int. 2014;2014:129145.

69. Doeppner TR, Hermann DM. Editorial: stem cells and progenitor cells in ischemic stroke-fashion or future? Front Cell Neurosci. 2015;9:334.

70. Hess DC, Blauenfeldt RA, Andersen G, Hougaard KD, Hoda MN, Ding Y, et al. Remote ischaemic conditioning-a new paradigm of self-protection in the brain. Nat Rev Neurol. 2015;11:698-710.

71. Khan MB, Hoda MN, Vaibhav K, Giri S, Wang P, Waller JL, et al. Remote ischemic postconditioning: harnessing endogenous protection in a murine model of vascular cognitive impairment. Transl Stroke Res. 2015;6:69-77.

72. Hoda MN, Bhatia K, Hafez SS, Johnson MH, Siddiqui S, Ergul A, et al. Remote ischemic perconditioning is effective after embolic stroke in ovariectomized female mice. Transl Stroke Res. 2014;5: 484-90.

73. Keep RF, Wang MM, Xiang J, Hua Y, Xi G. Full steam ahead with remote ischemic conditioning for stroke. Transl Stroke Res. 2014;5: $535-7$.

74. Liu X, Zhao S, Liu F, Kang J, Xiao A, Li F, et al. Remote ischemic postconditioning alleviates cerebral ischemic injury by attenuating endoplasmic reticulum stress-mediated apoptosis. Transl Stroke Res. 2014;5:692-700.
75. Qi Z, Dong W, Shi W, Wang R, Zhang C, Zhao Y, et al. Bcl-2 phosphorylation triggers autophagy switch and reduces mitochondrial damage in limb remote ischemic conditioned rats after ischemic stroke. Transl Stroke Res. 2015;6:198-206.

76. Han Z, Liu X, Luo Y, Ji X. Therapeutic hypothermia for stroke: where to go? Exp Neurol. 2015;272:67-77.

77. Ghuman H, Massensini AR, Donnelly J, Kim SM, Medberry CJ, Badylak SF, et al. ECM hydrogel for the treatment of stroke: characterization of the host cell infiltrate. Biomaterials. 2016;91:166-81.

78. Stabenfeldt SE, Munglani G, Garcia AJ, LaPlaca MC. Biomimetic microenvironment modulates neural stem cell survival, migration, and differentiation. Tissue Eng Part A. 2010;16:3747-58.

79. Massensini AR, Ghuman H, Saldin LT, Medberry CJ, Keane TJ, Nicholls FJ, et al. Concentration-dependent rheological properties of ECM hydrogel for intracerebral delivery to a stroke cavity. Acta Biomater. 2015;27:116-30.

80. Skop NB, Calderon F, Cho CH, Gandhi CD, Levison SW. Improvements in biomaterial matrices for neural precursor cell transplantation. Mol Cell Ther. 2014;2:19.

81. Langhorne P, Bernhardt J, Kwakkel G. Stroke rehabilitation. Lancet. 2011;377:1693-702.

82. Ploughman M, Austin MW, Glynn L, Corbett D. The effects of poststroke aerobic exercise on neuroplasticity: a systematic review of animal and clinical studies. Transl Stroke Res. 2015;6:13-28. 